\title{
Optimization of micro hardness of Al-SiC 6061 MMC machined by Wire EDM with Taguchi Method
}

\author{
Rohit Sharma, Vivek Aggarwal, H. S. Payal
}

\begin{abstract}
The usage of Al-SiC metal matrix composites is constantly increasing since the last many years due to their many unique properties such as light weight, high strength, high specific modulus, high fatigue strength, low density, and high hardness. However, because of their high hardness, their machining, that too within close tolerance limits, is often a big challenge. Wire EDM (Electric Discharge Machining) however offers a good method to machine these deemed difficult to machine alloys. This research work focuses on the wire EDM machining of Al-SiC 6061 metal matrix composite which is one of the most widely used metal matrix composites in the world today. Here, Taguchi approach has been applied to study the work-piece composition and machining parameters during the wire EDM machining and to maximize the micro hardness of the surface obtained after the machining process. Different compositions of the Al-SiC MMC in terms of reinforcement percentages, along with six other operating parameters have been studied. L-16 Orthogonal Array (pronounced as ell-sixteen Orthogonal Array) has been used in the Taguchi approach for this purpose. Contributions of various factors to surface micro hardness have been determined, amongst which, SiC percentage in the Al-SiC MMC had the greatest contribution. The conclusions and future scope of this study have also been discussed.
\end{abstract}

Keywords: Al SiC, 6061, composite, micro hardness, MMCs, Orthogonal Arrays, Taguchi, Wire Electric Discharge Machining.

\section{INTRODUCTION}

This work analyzes the various factors (also known as parameters) involved in the machining by wire-cut EDM machine. Conventional machine tools such as routers, saws, and lathes are often not suitable for machining composites and high strength alloys [1]. Wire EDM is hence one of the non-conventional methods used for machining such materials. It is one of the widely accepted advanced manufacturing processes used to machine complicated materials [2]. Elektra Supercut 734 was the wire EDM machine used by us for this work which uses a brass wire as cutting wire and deionized water as a dielectric.

Revised Manuscript Received on October 30, 2019.

* Correspondence Author

Rohit Sharma*, Research Scholar (PhD student), Department of Mechanical Engineering, IK Gujral Punjab Technical University, Punjab, India.

Dr. Vivek Aggarwal, Assistant Professor, Department of Mechanical Engineering, IK Gujral Punjab Technical University, Punjab, India.

Prof. (Dr.) H.S. Payal, Professor \& Head, Department of Mechanical Engineering, SRHU, Dehradun, India.

(C) The Authors. Published by Blue Eyes Intelligence Engineering and Sciences Publication (BEIESP). This is an open access article under the CC BY-NC-ND license (http://creativecommons.org/licenses/by-nc-nd/4.0/)
The dielectric is continuously kept in circulation through the machine and filtration unit in a closed circuit. Six factors of the machining process have been involved in this study, namely, the upper nozzle height, the wire feed rate, the (machining) current, the gap voltage, the (wire) tension, and the upper nozzle flow rate.

Along with these six factors, the percentage of $\mathrm{SiC}$ particles in $\mathrm{Al}-\mathrm{SiC} 6061$ metal matrix composite has also been studied at two levels as specimen composition. Levels are defined as the setting of various factors in a factorial experiment. The Taguchi experimental design has been used for this purpose. It provides an efficient and systematic approach for determining the optimum machining parameters in the manufacturing process [3].

The Al-SiC 6061 which has been used in this work is a Metal matrix composite. Metal matrix composites usually consist of a low-density metal such as aluminum or magnesium, reinforced with particulate or fibers of a ceramic material such as silicon carbide or graphite [4]. As a matter of fact, the most popular type of MMC is aluminum alloy reinforced with ceramic particles [5]. The two variations which have been studied in this work are that of $5 \% \mathrm{SiC}$ and of $10 \% \mathrm{SiC}$ reinforcements, respectively. Al$\mathrm{SiC} 6061 \mathrm{MMC}$ has the aluminum alloy of Al-6061 (called its matrix phase) with uniformly distributed $\mathrm{SiC}$ particles of 220 mesh size (called its reinforcement phase). An MMC having aluminum as its matrix phase is also sometimes called Aluminum Matrix Composite (AMC). These specimens had been prepared by Stir Casting (SC) process. Of various AMC manufacturing techniques, stir casting has the advantage of being the simplest, most flexible and cheapest process of all [6].

An Orthogonal Array (OA) is a mathematical invention recorded by Jacques Hadamard, a French mathematician in as early as 1897 [7]. Orthogonal Array of 1-16 type had been found to be most appropriate for the study, hence had been employed. A factor is another name of a parameter in experiments. The most favorable levels of each of the seven factors (six factors are the machining parameters of the machine, and the seventh factor is that of the specimen composition; hence total seven factors) have been found out. Percentage contribution of each of these factors has also been worked out which describe that how dominantly each of these factors contributes to the final hardness of machined surfaces on this machine. 


\section{MATERIALS AND METHODS}

Composition analysis of the Al-6061 alloy was done by atomic emission spectrometry as per the ASTM E1251-2011 test method. Its results were tallied with statistically available data regarding Al-6061 alloy and the alloy was deemed authentic and hence acceptable for further research. The test results have been shown in Table 1 below,

Table 1. Spectrometry test results of Alumimium 6061.

\begin{tabular}{|l|l|l|l|l|l|l|}
\hline $\begin{array}{l}\text { Elem } \\
\text { ent }\end{array}$ & $\mathbf{C u}$ & $\mathbf{M g}$ & $\mathbf{S i}$ & $\mathbf{F e}$ & $\mathbf{N i}$ & $\mathbf{M n}$ \\
\hline $\begin{array}{l}\text { Perce } \\
\text { ntage }\end{array}$ & $\begin{array}{l}0.20 \\
30\end{array}$ & $\begin{array}{l}0.93 \\
30\end{array}$ & $\begin{array}{l}0.78 \\
40\end{array}$ & $\begin{array}{l}0.30 \\
40\end{array}$ & $\begin{array}{l}0.00 \\
32\end{array}$ & $\begin{array}{l}0.083 \\
6\end{array}$ \\
\hline $\begin{array}{l}\text { Elem } \\
\text { ent }\end{array}$ & $\mathbf{Z n}$ & $\mathbf{P b}$ & $\mathbf{S n}$ & $\mathbf{T i}$ & $\mathbf{C r}$ & $\mathbf{A l}$ \\
\hline $\begin{array}{l}\text { Perce } \\
\text { ntage }\end{array}$ & 0.05 & $\begin{array}{l}0.02 \\
70\end{array}$ & $\begin{array}{l}< \\
0.01 \\
00\end{array}$ & $\begin{array}{l}0.06 \\
89\end{array}$ & $\begin{array}{l}0.04 \\
72\end{array}$ & $\begin{array}{l}\text { Rema } \\
\text { ining }\end{array}$ \\
\hline
\end{tabular}

MMC was prepared out of this Al-6061 by stir casting process. Stir casting method involves the incorporation of reinforcements into liquid matrix melt through continuously stirring resulting into vortex mixing that enables the proper distribution of the reinforcements. The mixture of metal and reinforcement, called slurry, is allowed to solidify inside the pre-fabricated mold cavity [8]. SiC powder of 220 mesh size had been taken as reinforcement phase and preheated to a temperature of $3500^{\circ} \mathrm{C}$. $\mathrm{SiC}$ is the best strengthening reinforcement since it is having a higher value of Vickers (hardness) [9]. This temperature was maintained for about half an hour so as to remove moisture and volatile matter. The carefully weighed Al-SiC alloy was heated in a vertical muffle furnace to about $850^{\circ} \mathrm{C}$, and the preheated $\mathrm{SiC}$ particles were then added to them. $1 \%$ by weight magnesium ribbon strip was also put in the crucible so as to increase the bonding of $\mathrm{SiC}$ particles with the molten Al-SiC. If the bonding between the two is weak, which can occur due to wettability issues or lack of interaction in-between, the final composite will have poor mechanical properties [10]. A stirrer of graphite was left to rotate in the molten slurry for some time. After removal of slag, the metal poured into two specially prepared cylinder molds, one with 5\% $\mathrm{SiC}$ composition and another of the $10 \% \mathrm{SiC}$ composition, respectively.

After preparation of the $5 \%$ and $10 \% \mathrm{SiC}$ specimens to be used for the final experimental work, SEM was carried out on the $10 \%$ specimen because the percentage of particles was more in it. Scanning Electron Microscope - JSM 6100 of JEOL make was used for this purpose. The result has been shown in Figure 1.

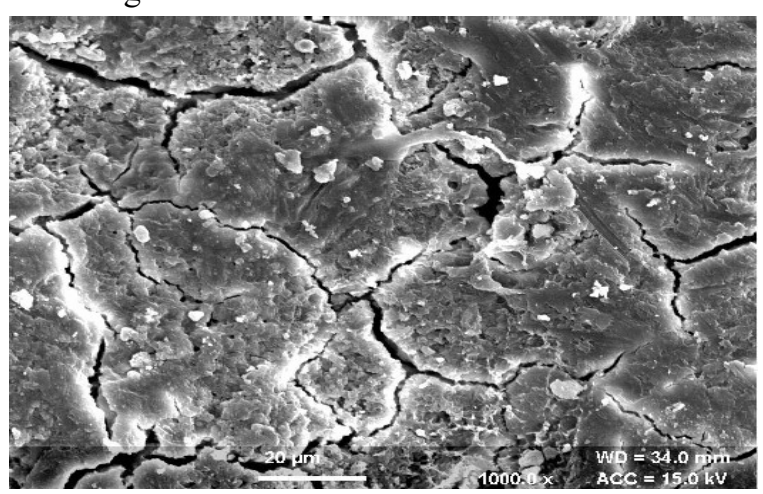

Retrieval Number F8472088619/2019@BEIESP DOI: 10.35940/ijeat.F8472.088619
Fig. 1. The SEM photograph showing $\mathrm{SiC}$ particles as the reinforcement phase which is embedded in the $\mathrm{Al} 6061$ as the matrix phase.

Taguchi design of experiments had been planned in order to investigate the effect of cutting parameters on these two specimens. It is an efficient test strategy which possesses many advantages because of its balanced arrangement. When each experimental run was decided in terms of various parameters and their levels, the machining cuts were performed on specimens by wire EDM machining so as to investigate the performance of machining of this MMC material on wire EDM machine. Wire electrical discharge machining is a particular thermal non-contact technique of machining [11]. It is a spark erosion process used to produce complex two and three-dimensional shapes through electrically conductive work-pieces [12]. It removes the material by erosion procedure. Series of constantly repeating electrical discharges emerge between the tool and the workpiece in a dielectric fluid and remove the material [13]. It is hence deemed suitable for machining of exceptionally hard materials with good electrical conductivity, especially the MMCs. The machining cuts which were performed on the specimens were 48 in number. These were carried out in accordance with the conditions described by the 1-16 orthogonal array. Each of these cuts was $14 \mathrm{~mm}$ deep, and all these cuts were placed mutually at an axial distance of $2.5 \mathrm{~mm}$. The model is shown in Figure 2, and the actual cut out pieces have been shown in Figure 3.

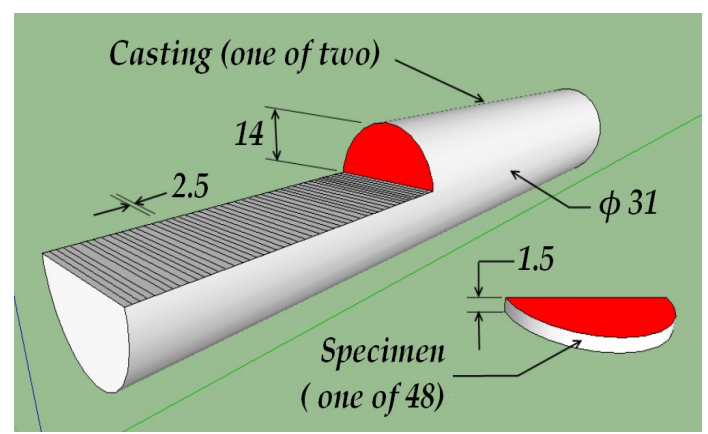

Fig. 2. The model showing the red colored surface being machined on a specimen. This is the surface which has been resulted from the first experimental setting and its hardness values are to be used in further analysis.

Fig. 3. The cut out semi-circular disc-shaped specimens

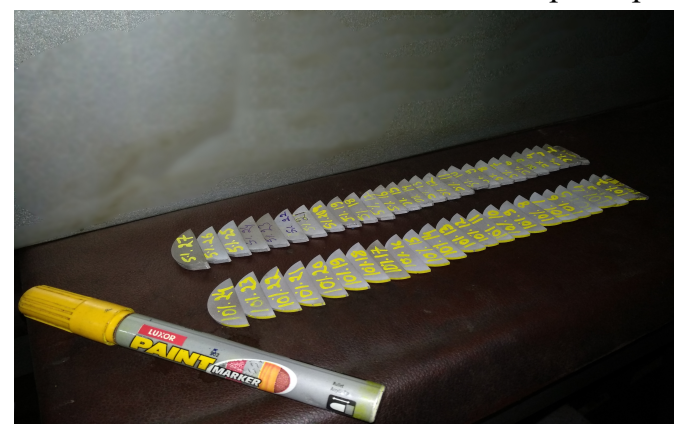

whose surfaces had to be analyzed for their micro hardness values and considered in the Taguchi method. 
Twenty four of these machining cuts had been done on the $5 \% \mathrm{SiC}$ MMC specimen and twenty four had been done on the $10 \% \mathrm{SiC}$ MMC specimen as per the guidelines of 1-16 orthogonal array in accordance with the Taguchi technique. The micro hardness values of these tests had been performed on the Rockwell hardness testing machine with diamond tip indenter, as shown in Figure 4 and Figure 5.

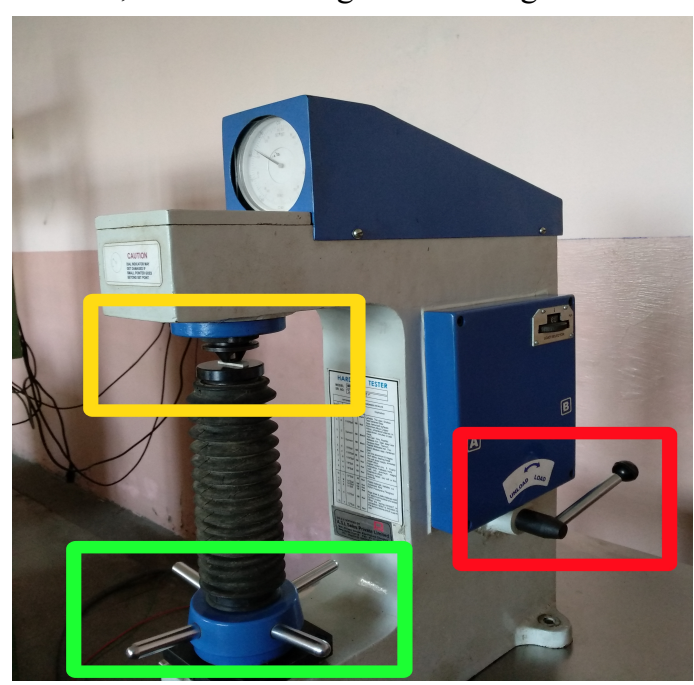

Fig. 4. Rockwell micro hardness testing machine (details). The yellow rectangle indicates the turret on which the specimen was needed to be placed, the green rectangle shows the hand wheel for application of minor load on the specimen, and the red rectangle shows the lever for the release of major load on the surface of specimen by the indenter. In order to conduct the micro hardness tests of the pieces obtained from the specimens after wire EDM machining, according to tables, the diamond tip indenter for a load of $60 \mathrm{~kg}$ was selected. This indenter was mounted on the turret upside down over the test table by us. After a specific semi-circular disc-shaped specimen was placed with its test surface towards the top on the test table whose position has been shown by a yellow circle, the hand wheel beneath it was rotated by us so as to raise it to touch the indenter. The indenter has been explained briefly in Figure 5 .

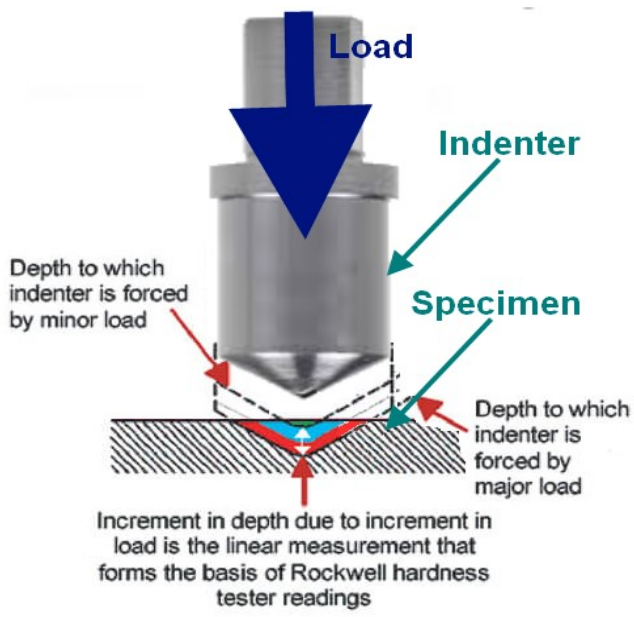

Fig. 5. The increment in depth is a measure of hardness of specimen in a diamond rockwell tester.

\section{RESULTS AND DISCUSSION}

\subsection{Design of experiments}

For the sake of accuracy, five readings had been taken on the surface of each specimen at various random places, and their averages had been considered in the study. This was done in accordance with the concept of repetition. These are the 16 settings which have been directed by the 1-16 orthogonal array in accordance to which these tests had been performed. Table 2 shows these 16 values which we next used in the orthogonal array.

Table 2. Average micro hardness obtained during machining at each setting of Orthogonal Array (numbered 1 to 16).

\begin{tabular}{|c|c|c|c|c|}
\hline S. & Specimen & $\begin{array}{l}\text { Specimen } \\
17 \text { to } 32\end{array}$ & $\begin{array}{l}\text { Specimen } \\
33 \text { to } 48\end{array}$ & $\begin{array}{l}\text { Average } \\
(1 \text { to } 16)\end{array}$ \\
\hline $1 \mathbf{N} 0$. & HRA) & HRA) & HRA) & HRA) \\
\hline 1 & 75.2 & 72.4 & 83.6 & 77.1 \\
\hline 2 & 77.4 & 61.6 & 90.6 & 76.5 \\
\hline 3 & 84.6 & 87.2 & 88.2 & 86.7 \\
\hline 4 & 83.8 & 91.2 & 89.4 & 88.1 \\
\hline 5 & 83.2 & 89.8 & 91.8 & 88.3 \\
\hline 6 & 84 & 88.4 & 92.6 & 88.3 \\
\hline 7 & 67.4 & 85.4 & 85.6 & 79.5 \\
\hline 8 & 77.4 & 84.4 & 86 & 82.6 \\
\hline 9 & 71.8 & 84.2 & 88.6 & 81.5 \\
\hline 10 & 76.6 & 84 & 87.2 & 82.6 \\
\hline 11 & 87.6 & 87.4 & 87 & 87.3 \\
\hline 12 & 85 & 89.8 & 90.4 & 88.4 \\
\hline 13 & 86.6 & 88.4 & 90.8 & 88.6 \\
\hline 14 & 89.8 & 86.6 & 89.6 & 88.7 \\
\hline 15 & 84 & 77 & 92.4 & 84.5 \\
\hline 16 & 73.2 & 87.8 & 81 & 80.7 \\
\hline
\end{tabular}

As per the standard method of Taguchi analysis of orthogonal arrays, these 16 values had been placed on the right side of the 1-16 orthogonal array (in orange colored blocks). Rows and columns have been colored for better comprehension, as shown in Table 3 below.

Table 3. Orthogonal Array 116 for micro hardness.

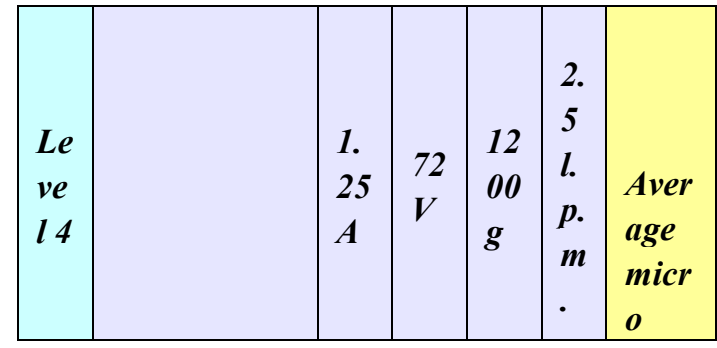

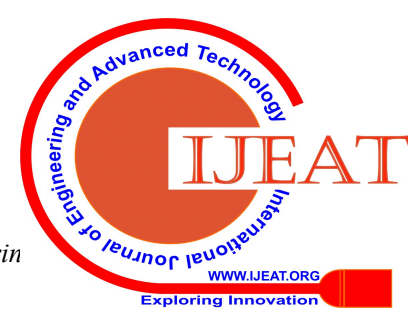




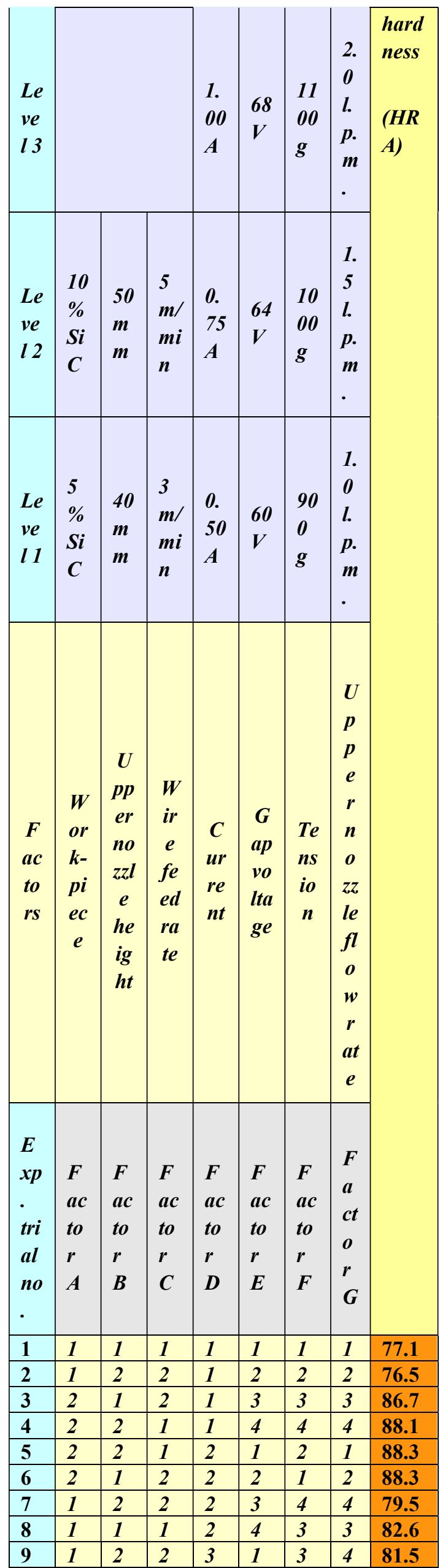

\begin{tabular}{|l|l|l|l|l|l|l|l|l|}
10 & 1 & 1 & 1 & 3 & 2 & 4 & 3 & 82.6 \\
\hline 11 & 2 & 2 & 1 & 3 & 3 & 1 & 2 & 87.3 \\
\hline 12 & 2 & 1 & 2 & 3 & 4 & 2 & 1 & 88.4 \\
\hline 13 & 2 & 1 & 2 & 4 & 1 & 4 & 2 & 88.6 \\
\hline 14 & 2 & 2 & 1 & 4 & 2 & 3 & 1 & 88.7 \\
\hline 15 & 1 & 1 & 1 & 4 & 3 & 2 & 4 & 84.5 \\
\hline 16 & 1 & 2 & 2 & 4 & 4 & 1 & 3 & 80.7 \\
\hline
\end{tabular}

\subsection{Mathematical analysis}

\subsubsection{Calculations for Average Effects of micro hardness}

Based on Table 3 given above, next, the Average Effects of micro hardness were calculated. The calculations have been shown below.

Average Effects of A at levels 1 and 2,

$\mathrm{A}_{1}=(77.1+76.5+79.5+82.5+81.5+82.6+$ $84.5+80.7) / 8=80.625$,

$\mathrm{A}_{2}=(86.7+88.1+88.3+88.3+87.3+88.4+$ $88.6+88.7) / 8=88.050$.

Average Effects of B at levels 1 and 2,

$\mathrm{B}_{1}=(77.1+86.7+88.3+82.6+82.6+88.4+$ $88.6+84.5) / 8=84.850$

$\mathrm{B}_{2}=(76.5+88.1+88.3+79.5+81.5+87.3+$ $88.7+80.7) / 8=83.825$.

Average Effects of $\mathrm{C}$ at levels 1 and 2,

$\mathrm{C}_{1}=(77.1+88.1+88.3+82.6+82.6+87.3+$ $88.7+84.5) / 8=84.900$

$\mathrm{C}_{2}=(76.5+86.7+88.3+79.5+81.5+88.4+$ $88.6+80.7) / 8=84.338$.

Average Effects of D at levels 1, 2, 3, and 4,

$\mathrm{D}_{1}=(77.1+76.5+86.7+88.1) / 4=82.100$,

$\mathrm{D}_{2}=(88.3+88.3+79.5+82.6) / 4=84.675$,

$\mathrm{D}_{3}=(81.5+82.6+87.3+88.4) / 4=84.950$,

$\mathrm{D}_{4}=(88.6+88.7+84.5+80.7) / 4=85.625$.

Average Effects of $E$ at levels 1, 2, 3, and 4,

$$
\begin{aligned}
& \mathrm{E}_{1}=(77.1+88.3+81.5+88.6) / 4=83.875, \\
& \mathrm{E}_{2}=(76.5+88.3+82.6+88.7) / 4=84.025, \\
& \mathrm{E}_{3}=(86.7+79.5+87.3+84.5) / 4=84.500, \\
& \mathrm{E}_{4}=(88.1+82.6+88.4+80.7) / 4=84.950
\end{aligned}
$$

Average Effects of $\mathrm{F}$ at levels 1, 2, 3, and 4,

$$
\begin{aligned}
& \mathrm{F}_{1}=(77.1+88.3+87.3+80.7) / 4=83.350 \\
& \mathrm{~F}_{2}=(76.5+88.3+88.4+84.5) / 4=84.425, \\
& \mathrm{~F}_{3}=(86.7+82.6+81.5+88.7) / 4=84.875, \\
& \mathrm{~F}_{4}=(88.1+79.5+82.6+88.6) / 4=84.700
\end{aligned}
$$

Average Effects of $\mathrm{G}$ at levels 1, 2, 3, and 4,

$$
\begin{aligned}
& \mathrm{G}_{1}=(77.1+88.3+88.4+88.7) / 4=85.625, \\
& \mathrm{G}_{2}=(76.5+88.3+87.3+88.6) / 4=85.175, \\
& \mathrm{G}_{3}=(86.7+82.6+82.6+80.7) / 4=83.150, \\
& \mathrm{G}_{4}=(88.1+79.5+81.5+84.5) / 4=83.400 .
\end{aligned}
$$

These Average Effects can be summarized, as shown in Table 4. 
Table 4. The Average Effects.

\begin{tabular}{|c|c|c|c|c|c|}
\hline $\begin{array}{l}F \\
a \\
c \\
t \\
o \\
r\end{array}$ & Factor name & $\begin{array}{l}\text { Level } \\
1, \mathrm{~L} 1\end{array}$ & $\begin{array}{l}\text { Level } \\
2, \mathrm{~L} 2\end{array}$ & $\begin{array}{l}\text { Level } \\
3, \mathrm{L3}\end{array}$ & $\begin{array}{l}\text { Level } \\
4, \mathrm{~L} 4\end{array}$ \\
\hline A & Work-piece & 80.62 & 88.05 & - & - \\
\hline $\mathrm{B}$ & $\begin{array}{l}\text { Upper nozzle } \\
\text { height }\end{array}$ & 84.85 & 83.82 & - & - \\
\hline $\mathrm{C}$ & Wire feed rate & 84.90 & 84.33 & - & - \\
\hline $\mathrm{D}$ & Current & 82.10 & 84.67 & 84.95 & 85.62 \\
\hline $\mathrm{E}$ & Gap voltage & 83.87 & 84.02 & 84.50 & 84.95 \\
\hline $\mathrm{F}$ & Tension & 83.35 & 84.42 & 84.87 & 84.70 \\
\hline G & $\begin{array}{l}\text { Upper nozzle } \\
\text { flow rate }\end{array}$ & 85.62 & 85.17 & 83.15 & 83.40 \\
\hline
\end{tabular}

3.2.2. Calculations for sum of squares of factors and their percentage contribution

Based on Table 4 given above, next, the sum of squares of each factor is calculated. Furthermore, the sum of squares have been used to calculate the percent contribution of various factors for micro hardness. This has been shown in Table 5 to Table 8 below.

Table 5. Means of Levels (to calculate Percent Contribution for micro hardness).

\begin{tabular}{|c|c|c|c|c|c|}
\hline $\begin{array}{l}F \\
a c \\
t o \\
r\end{array}$ & $\begin{array}{c}\text { Level } \\
1, L 1\end{array}$ & $\begin{array}{c}\text { Level } \\
2, \mathrm{~L} 2\end{array}$ & $\begin{array}{l}\text { Level } \\
3, \text { L3 }\end{array}$ & $\begin{array}{l}\text { Level } \\
4, \text { L4 }\end{array}$ & $\begin{array}{c}\text { Mean } \\
\text { of } \\
\text { Level } \\
s\left(x_{m}\right)\end{array}$ \\
\hline A & 80.62 & 88.05 & - & - & 84.34 \\
\hline B & 84.85 & 83.82 & - & - & 84.33 \\
\hline $\mathrm{C}$ & 84.90 & 83.77 & - & - & 84.33 \\
\hline $\mathrm{D}$ & 82.10 & 84.67 & 84.95 & 85.62 & 84.33 \\
\hline $\mathrm{E}$ & 83.87 & 84.02 & 84.50 & 84.95 & 84.33 \\
\hline $\mathrm{F}$ & 83.35 & 84.42 & 84.87 & 84.70 & 84.33 \\
\hline $\mathrm{G}$ & 85.62 & 85.17 & 83.15 & 83.40 & 84.33 \\
\hline
\end{tabular}

Table 6. Calculations of Percent Contribution for micro hardness.

\begin{tabular}{|l|l|l|l|l|}
\hline$F$ & $L 1-x_{m}$ & $L 2-x_{m}$ & $L 3-x_{m}$ & $L 4-x_{m}$ \\
\hline
\end{tabular}

\begin{tabular}{|l|l|l|l|l|}
\hline $\begin{array}{c}\text { ac } \\
\boldsymbol{r} \boldsymbol{r}\end{array}$ & & & & \\
\hline $\mathrm{A}$ & -3.713 & 3.712 & - & - \\
\hline $\mathrm{B}$ & 0.512 & -0.513 & - & - \\
\hline $\mathrm{C}$ & 0.562 & -0.563 & - & - \\
\hline $\mathrm{D}$ & -2.238 & 0.337 & 0.612 & 1.287 \\
\hline E & -0.463 & -0.313 & 0.162 & 0.612 \\
\hline F & -0.988 & 0.087 & 0.537 & 0.362 \\
\hline G & 1.287 & 0.837 & -1.188 & -0.938 \\
\hline
\end{tabular}

Table 7. Sum of squares (to calculate Percent Contribution for micro hardness).

\begin{tabular}{|c|c|c|c|c|c|}
\hline $\begin{array}{l}\text { Fa } \\
\text { cto } \\
\text { r }\end{array}$ & $\begin{array}{l}(\mathrm{L1}- \\
\left.\mathbf{x}_{\mathrm{m}}\right)^{2}\end{array}$ & $\begin{array}{l}(\mathrm{L} 2- \\
\left.\mathbf{x}_{\mathrm{m}}\right)^{2}\end{array}$ & $\begin{array}{l}(\mathrm{L3}- \\
\left.\mathbf{x}_{\mathrm{m}}\right)^{2}\end{array}$ & $\begin{array}{l}(\mathrm{L} 4- \\
\left.\mathbf{x}_{\mathrm{m}}\right)^{2}\end{array}$ & $\Sigma$ \\
\hline A & $\begin{array}{l}13.7 \\
86\end{array}$ & $\begin{array}{l}13.7 \\
79\end{array}$ & - & - & $\begin{array}{l}27.56 \\
5\end{array}$ \\
\hline B & $\begin{array}{l}0.26 \\
2\end{array}$ & $\begin{array}{l}0.26 \\
3\end{array}$ & - & - & 0.525 \\
\hline $\mathrm{C}$ & $\begin{array}{l}0.31 \\
6\end{array}$ & $\begin{array}{l}0.31 \\
7\end{array}$ & - & - & 0.633 \\
\hline $\mathrm{D}$ & $\begin{array}{l}5.00 \\
9\end{array}$ & $\begin{array}{l}0.11 \\
4\end{array}$ & $\begin{array}{l}0.37 \\
5\end{array}$ & $\begin{array}{l}1.65 \\
6\end{array}$ & 7.153 \\
\hline$E$ & $\begin{array}{l}0.21 \\
4\end{array}$ & $\begin{array}{l}0.09 \\
8\end{array}$ & $\begin{array}{l}0.02 \\
6\end{array}$ & $\begin{array}{l}0.37 \\
5\end{array}$ & 0.713 \\
\hline $\mathrm{F}$ & $\begin{array}{l}0.97 \\
6\end{array}$ & $\begin{array}{l}0.00 \\
8\end{array}$ & $\begin{array}{l}0.28 \\
8\end{array}$ & $\begin{array}{l}0.13 \\
1\end{array}$ & 1.403 \\
\hline G & $\begin{array}{l}1.65 \\
6\end{array}$ & $\begin{array}{l}0.70 \\
1\end{array}$ & $\begin{array}{l}1.41 \\
1\end{array}$ & $\begin{array}{l}0.88 \\
0\end{array}$ & 4.648 \\
\hline
\end{tabular}

Table 8. Percent Contribution for micro hardness.

\begin{tabular}{|l|l|l|l|}
\hline $\mathbf{F}$ & $\boldsymbol{\Sigma}$ & D.F & \multicolumn{1}{|c|}{ Sum of } \\
ac & & $\begin{array}{l}\text { squares } \\
\text { to }\end{array}$ & \\
r & & & \\
\hline A & 27.565 & 1 & 27.565 \\
\hline B & 0.525 & 1 & 0.525 \\
\hline C & 0.633 & 1 & 0.633 \\
\hline
\end{tabular}




\begin{tabular}{|l|l|l|l|}
$\mathrm{D}$ & 7.153 & 3 & 2.384 \\
\hline $\mathrm{E}$ & 0.713 & 3 & 0.238 \\
\hline $\mathrm{F}$ & 1.403 & 3 & 0.468 \\
\hline $\mathrm{G}$ & 4.648 & 3 & 1.549 \\
\hline
\end{tabular}

The percent contribution of various factors has been shown graphically in Figure 6.

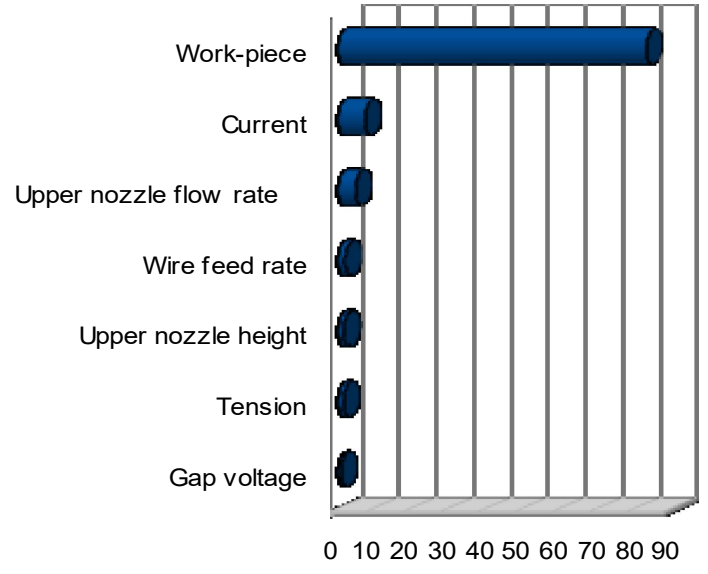

Fig. 6. A bar chart showing the percent contribution of various factors in the wire EDM machining of Al-SiC 6061 alloy.

3.3. Determination of factor levels for achieving maximum micro hardness values

As per the Taguchi technique, the main effects of micro hardness need to be plotted graphically for each factor, one by one. This was done by us by plotting the Average Effects of that factor on two-dimensional graph, as shown in Figure 7.

\subsubsection{Main effects of factor $A$}

In the context of the $\mathrm{SiC}$ percentage of both the specimens, the plots of the main effects have been shown below.

We plotted the Average Effects, depicted in Table 4 along the $\mathrm{y}$-axis and the levels of factors along the $\mathrm{x}$-axis in Figure 7.

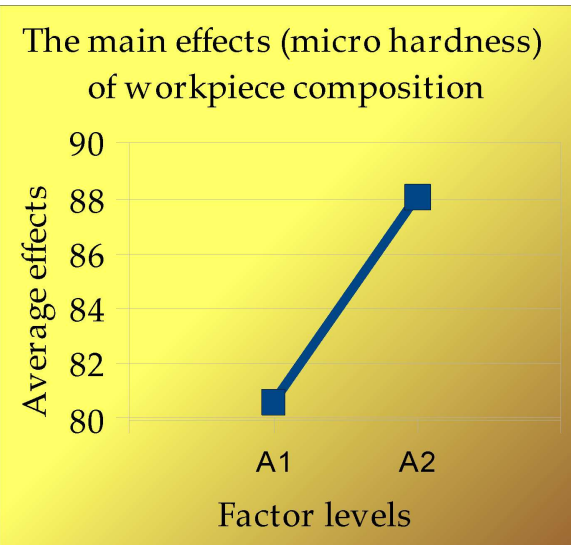

Fig. 7. Graphical representation of the main effects of factor A (both specimens' $\mathrm{SiC}$ percentage). Y-axis has Average Effects in units of HRA and $\mathrm{X}$-axis has $5 \% \mathrm{SiC}$ composition specimen as $\mathrm{A} 1$ and $10 \% \mathrm{SiC}$ composition as $\mathrm{A} 2$.

The micro hardness needs to be maximized. Hence, on the visual examination of Figure 7 above, we see that the factor level that shall result in a higher value of micro hardness is A2.

\subsubsection{Main effects of factor $B$}

In the context of the upper nozzle height of the wire EDM machine, the plots of the main effects have been shown below.

We plotted the Average Effects, depicted in Table 4 along the $\mathrm{y}$-axis and the levels of factors along the $\mathrm{x}$-axis in Figure 8 .

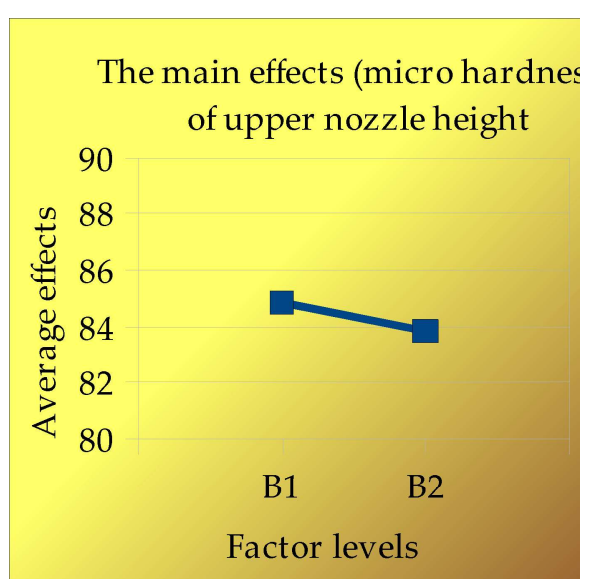

Fig. 8. Graphical representation of the main effects of factor $\mathrm{B}$ (upper nozzle height). Y-axis has Average Effects in units of HRA and X-axis has $40 \mathrm{~mm}$ as B1 and $50 \mathrm{~mm}$ as B2.

The micro hardness needs to be maximized. Hence, on the visual examination of Figure 8 above, we see that the factor level that shall result in a higher value of micro hardness is B1.

\subsubsection{Main effects of factor $C$}

In the context of the wire feed rate, the plots of the main effects have been shown below.

We plotted the Average Effects, depicted in Table 4 along the $\mathrm{y}$-axis and the levels of factors along the $\mathrm{x}$-axis in Figure 9.

Fig. 9. Graphical representation of the main effects of factor

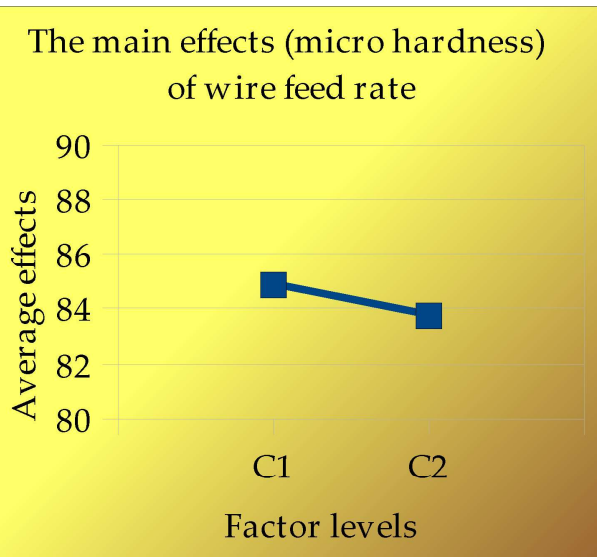

$\mathrm{C}$ (wire feed rate). Y-axis has Average Effects in units of HRA and $\mathrm{X}$-axis has wire feed rate as level $\mathrm{C} 1$ and level $\mathrm{C} 2$ in units of $\mathrm{m} / \mathrm{min}$.

The micro hardness needs to be maximized. Hence, on the visual examination of Figure 9 above, we see that the factor level that shall result in a higher value of micro hardness is C1.

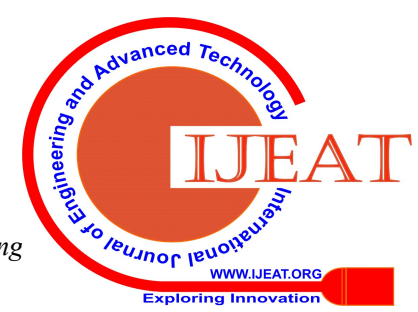




\subsubsection{Main effects of factor $D$}

In the context of the (machining) current used in the Wire EDM machine, the plots of the main effects have been shown below.

We plotted the Average Effects, depicted in Table 4 along the $\mathrm{y}$-axis and the levels of factors along the $\mathrm{x}$-axis in Figure 10.

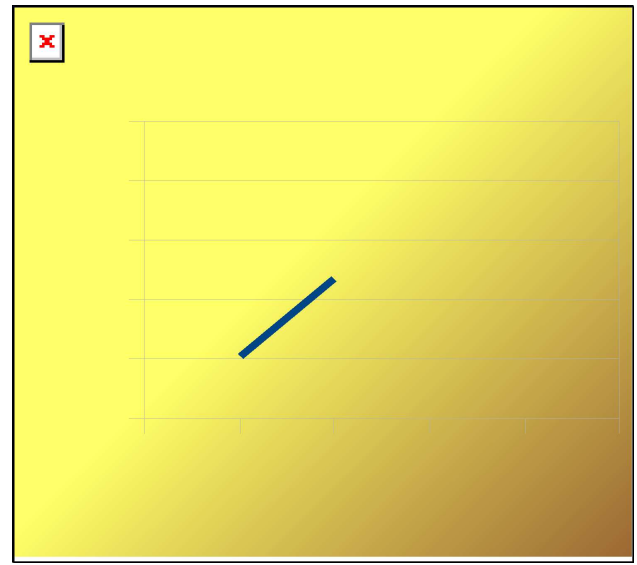

Fig. 10. Graphical representation of the main effects of factor D (machining current). Y-axis has Average Effects in units of HRA and X-axis has machining current as a factor at levels D1, D2, D3, and D4 in units of amperes.

The micro hardness needs to be maximized. Hence, on the visual examination of Figure 10 above, we see that the factor level that shall result in a higher value of micro hardness is D3.

\subsubsection{Main effects of factor $E$}

In the context of the gap voltage between the electrode wire of the Wire EDM machine and the workpiece to be machined, the plots of the main effects have been shown below.

We plotted the Average Effects, depicted in Table 4 along the $\mathrm{y}$-axis and the levels of factors along the $\mathrm{x}$-axis in Figure 11 .

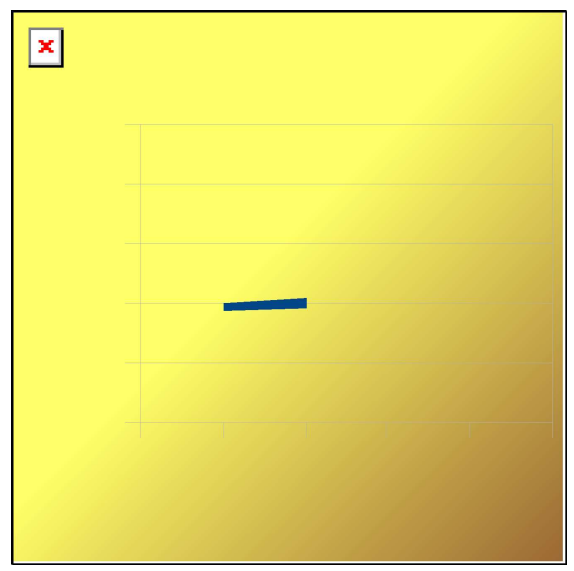

Fig. 11. Graphical representation of the main effects of factor E (gap voltage ). Y-axis has Average Effects in units of HRA and $\mathrm{X}$-axis has gap voltage as a factor at levels E1, $\mathrm{E} 2, \mathrm{E} 3$, and E4 in units of volts.

The micro hardness needs to be maximized. Hence, on the visual examination of Figure 11 above, we see that the factor level that shall result in a higher value of micro hardness is E4.

\subsubsection{Main effects of factor $F$}

In the context of the wire tension in the (machining) wire of Wire EDM machine, the plots of the main effects have been shown below.

We plotted the Average Effects, depicted in Table 4 along the $\mathrm{y}$-axis and the levels of factors along the $\mathrm{x}$-axis in Figure 12 .

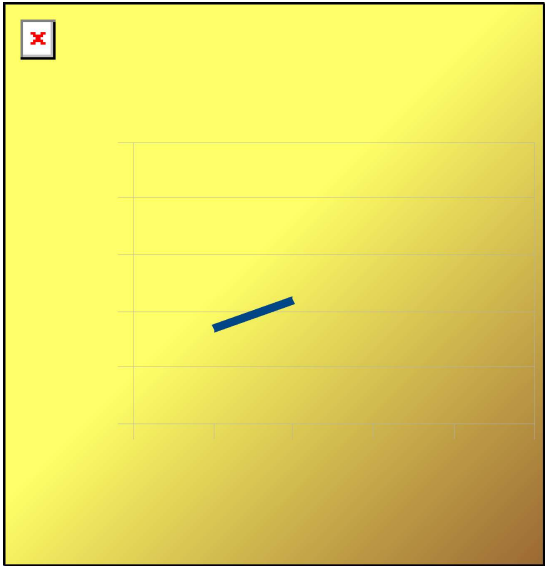

Fig. 12. Graphical representation of the main effects of factor $\mathrm{F}$ (wire tension ). Y-axis has Average Effects in units of HRA and $\mathrm{X}$-axis has (wire) tension as a factor at levels F1, F2, F3, and F4 in units of grams.

The micro hardness needs to be maximized. Hence, on the visual examination of Figure 12 above, we see that the factor level that shall result in a higher value of micro hardness is F3.

\subsubsection{Main effects of factor $G$}

In the context of the upper nozzle flow rate, the plots of the main effects have been shown below.

We plotted the Average Effects, depicted in Table 4 along the $\mathrm{y}$-axis and the levels of factors along the $\mathrm{x}$-axis in Figure 13 .

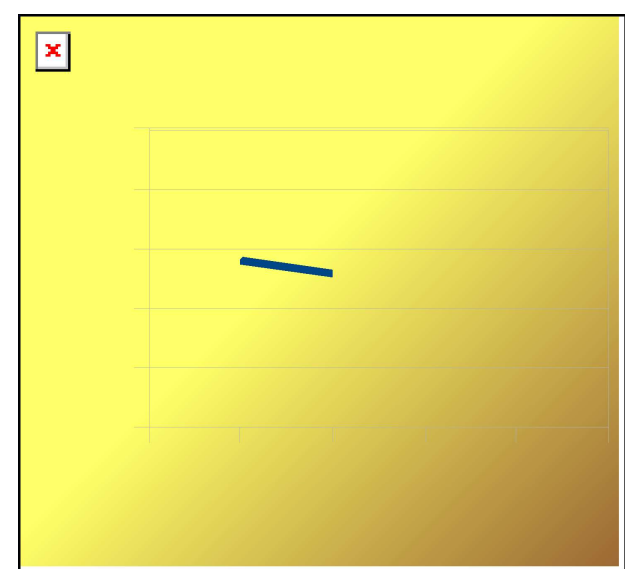

Fig. 13. Graphical representation of the main effects of factor $G$ (upper nozzle flow rate). Y-axis has Average Effects in units of HRA and X-axis has upper nozzle flow rate as a factor at levels G1, G2, G3, and G4 in units of l.p.m.

The micro hardness needs to be maximized. Hence, on the visual examination of Figure 13 above, we see that the factor level that shall result in a higher value of micro hardness is G1.

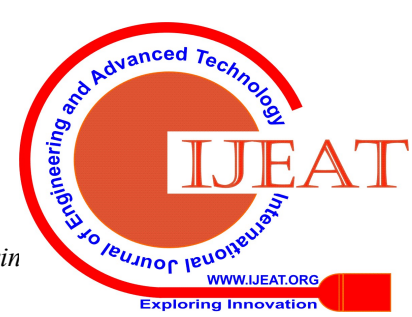


From the visual examination of figures above, we see that the levels of various factors that shall result in a high value of micro hardness correspond to $A_{2} B_{1} C_{1} D_{3} E_{4} F_{3} G_{1}$. The levels of various factors that shall result in a high value of micro hardness can be shown in tabular form, as in Table 9.

Table 9. Levels of factors for maximization of micro hardness.

\begin{tabular}{|l|l|l|l|}
\hline $\begin{array}{l}\text { Factor } \\
\text { Name }\end{array}$ & $\begin{array}{l}\text { Factor } \\
\text { Description }\end{array}$ & $\begin{array}{l}\text { Factor } \\
\text { Levels }\end{array}$ & $\begin{array}{l}\text { Factor } \\
\text { Values }\end{array}$ \\
\hline A & Work-piece & $\mathbf{A}_{2}$ & $\mathrm{SiC} 10 \%$ \\
\hline $\mathrm{B}$ & $\begin{array}{l}\text { Upper nozzle } \\
\text { height }\end{array}$ & $\mathbf{B}_{1}$ & $40 \mathrm{~mm}$ \\
\hline $\mathrm{C}$ & Wire feed rate & $\mathbf{C}_{1}$ & $3 \mathrm{~m} / \mathrm{min}$ \\
\hline $\mathrm{D}$ & Current & $\mathbf{D}_{3}$ & $1 \mathrm{~A}$ \\
\hline $\mathrm{E}$ & Gap voltage & $\mathbf{E}_{4}$ & $72 \mathrm{~V}$ \\
\hline $\mathrm{F}$ & Tension & $\mathbf{F}_{3}$ & $1100 \mathrm{~g}$ \\
\hline $\mathrm{G}$ & $\begin{array}{l}\text { Upper nozzle flow } \\
\text { rate }\end{array}$ & $\mathbf{G}_{1}$ & $11 . \mathrm{p} . \mathrm{m}$. \\
\hline
\end{tabular}

It is deemed that the above-mentioned levels of the given factors were to result in a higher value of micro hardness. 3.4. Projection of optimal performance (micro hardness) According to the usual notations, here,

Total number of observations, $\mathrm{N}=16$

Sum total of all observations, $\mathrm{T}$

$$
=77.1+76.5+86.7+88.1+88.3+88.3+79.5+
$$$$
82.6+81.5+82.6+87.3+88.4+88.6+88.7+
$$

$$
84.5+80.7
$$

$$
=1349.4 \text {. }
$$

Optimal performance, $\mathrm{Y}_{\text {optimal }}$

$$
\begin{aligned}
& =\mathrm{T} / \mathrm{N}+\left(\mathrm{A}_{2}-\mathrm{T} / \mathrm{N}\right)+\left(\mathrm{B}_{1}-\mathrm{T} / \mathrm{N}\right)+\left(\mathrm{C}_{1}-\mathrm{T} / \mathrm{N}\right)+ \\
& \left(\mathrm{D}_{3}-\mathrm{T} / \mathrm{N}\right)+\left(\mathrm{E}_{4}-\mathrm{T} / \mathrm{N}\right)+\left(\mathrm{F}_{3}-\mathrm{T} / \mathrm{N}\right)+\left(\mathrm{G}_{1}-\right. \\
& \mathrm{T} / \mathrm{N}) \\
& =84.338+(88.050-84.338)+(84.850-84.338)+ \\
& (84.900-84.338)+(84.950-84.338)+(84.950- \\
& 84.338)+(84.875-84.338)+(85.625-84.338), \\
& =84.338+(3.712)+(0.512)+(0.562)+(0.612) \\
& +(0.612)+(0.537)+(1.287) \\
& =\text { 92.172 HRA. }
\end{aligned}
$$

\section{CONFIRMATION TESTS}

It is recommended that the projected optimal performance should be checked by running confirmatory tests. After the aforesaid calculations were made, confirmatory experiments were carried out by us as per the parameter settings of Table 9. A total of three tests were performed by us, and hence, we prepared three specimens. All these specimens were prepared by us from the $\mathrm{SiC} 10 \%$ composition casting which corresponds to A2. In order to prepare these specimens, the $\mathrm{SiC} 10 \%$ composition casting was mounted by us on the Wire EDM machine. We set the various parameters according to the Table 9, after which, the machining cuts were made on the casting. This resulted in three specimens which had been cut on the parameter settings recommended for obtaining maximum micro hardness value. Similar to the earlier cut specimens during the test, the micro hardness values were measured by us on all these three specimens at five random points on their surfaces on the same micro hardness testing machine, and the average of these five points was taken by us. Then we took the average micro hardness values of these three specimens. The readings have been shown in Table 10 below.

Table 10. Confirmation tests for micro hardness.

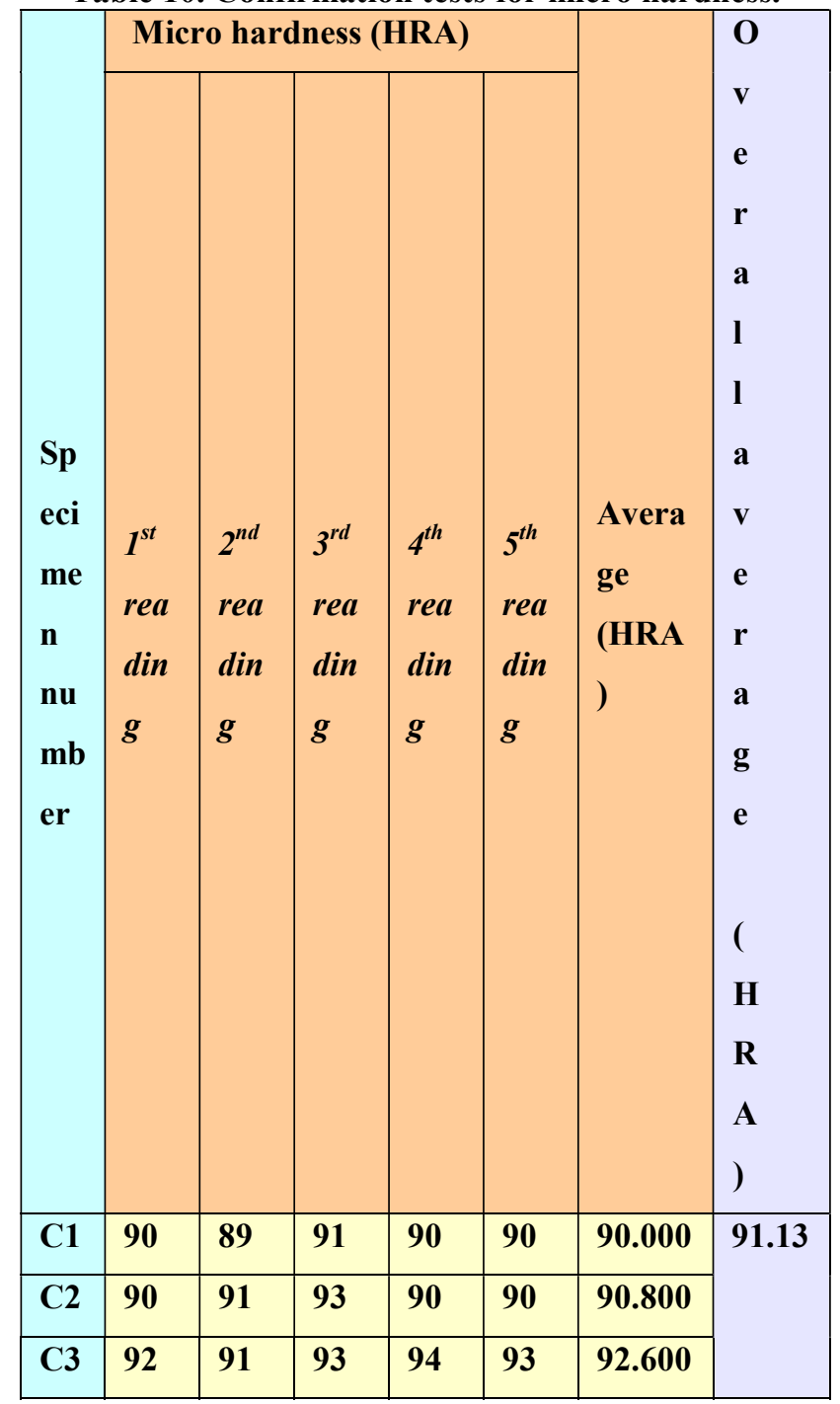

These results have been shown graphically in Figure 14 on being compared with their accuracy of predicted values.

The value of micro hardness which had been calculated by projection of optimal performance are $101.143 \%$ of the actual values which are quite satisfactory.

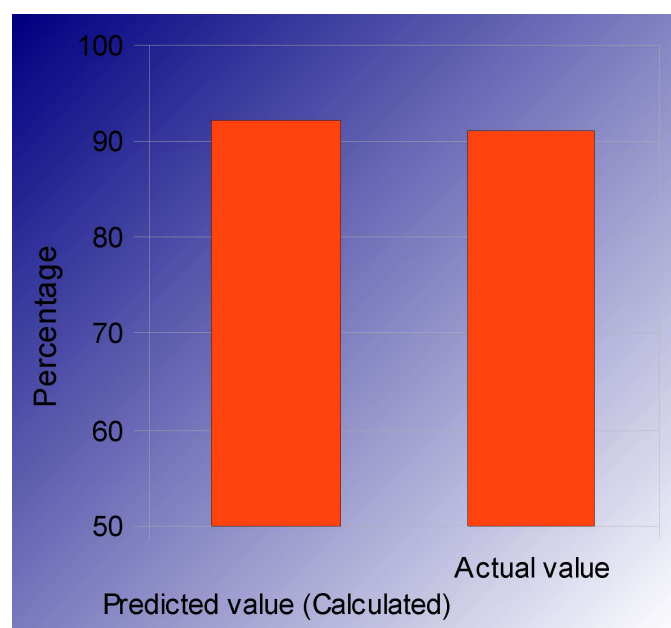

Fig. 14. Comparison of predicted and actual values of micro hardness obtained after the confirmation tests. 


\section{CONCLUSION}

It has been found out by us in this study that during the machining of Al-SiC MMC material carried out on a Wire EDM machine, the factor which most significantly affects the micro hardness of the specimens is the work-piece composition, that is, the percentage of reinforcement phase, $\mathrm{SiC}$ particles in this case. Clearly, a $10 \% \mathrm{SiC}$ composition aluminum MMC gives greater hardness values than $5 \% \mathrm{SiC}$ composition one. Similar had been the results by Karthick, Mathai, Tony, and Marikkannan in an earlier study regarding magnesium based MMCs [14]. After that, the various factors which affect the micro hardness values of surface machined out by Wire EDM machine in the decreasing order of significance are (machining) current, upper nozzle flow rate, wire feed rate, upper nozzle height, wire tension, and gap voltage, respectively. We observed that with the design of experiments being done in accordance with the Taguchi technique, we were able to achieve quite high values of surface micro hardness. Wire EDM is a non conventional machining process employed for the machining of difficult to machine materials which are too hard to be machined by conventional processes. Hardness is an important property which should be preserved and enhanced during a machining process. This research work puts forward an experimental technique by which an optimal combination of parameters may be determined which results in higher values of surface micro hardness. This is liable to result in higher operating lives of products obtained after machining, for example, the extrusion dies which are obtained by the operation of taper cutting carried on wire EDM machines. It also lays down a possibility that the micro hardness values can be planned well in advance of the surfaces which shall be obtained during wire EDM machining. For example, in order to obtain less brittle surface in some specific requirement, lower values of micro hardness could also be achieved by this method.

\section{REFERENCES}

1. Liu, “"7M'Advantage of Abrasive Waterjet for Machining Advanced Materials," Journal of Manufacturing and Materials Processing, vol 1, no. 1, p. 11, Sep. 2017.

2. P. R. Vundavilli, J. Phani Kumar, and C. Sai Priyatham, "Parameter optimization of wire electric discharge machining process using GA and PSO," in IEEE-International Conference On Advances In Engineering, Science And Management (ICAESM -2012), 2012, pp. 180-185.

3. Y. Ahmed, H. Youssef, H. El-Hofy, and M. Ahmed, "Prediction and Optimization of Drilling Parameters in Drilling of AISI 304 and AISI 2205 Steels with PVD Monolayer and Multilayer Coated Drills," Journal of Manufacturing and Materials Processing, vol. 2, no. 1, p. 16, Mar. 2018

4. Advanced Materials by design. Washington DC, US Government Printing Office, chapter 1, p. 9, 1988.

5. N . Muthukrishnan, J. Davim, "Optimization of Machining Parameters of $\mathrm{Al} / \mathrm{SiC}-\mathrm{MMC}$ with ANOVA and ANN Analysis," Journal of Materials Processing Technology, vol. 209, no. 1, p. 225232, 2009

6. K. V. Prasad and K. R. Jayadevan, "Simulation of Stirring in Stir Casting," Procedia Technology, vol. 24, pp. 356-363, 2016.

7. P. Ross, "Taguchi Techniques for Quality Engineering: Loss Function, Orthogonal Experiments, Parameter and Tolerance Design," McGraw-Hill, ISBN 978-0442237295, 1996.

8. R. Singh, R. Singh, J. S. Dureja, I. Farina, and F. Fabbrocino, "Investigations for dimensional accuracy of Al alloy/Al-MMC developed by combining stir casting and ABS replica based investment casting," Composites Part B: Engineering, vol. 115, pp 203-208, Apr. 2017.
9. A. Satpathy, S. Tripathy, N. P. Senapati, and M. K. Brahma, "Optimization of EDM process parameters for AlSiC- $20 \% \mathrm{SiC}$ reinforced metal matrix composite with multi response using TOPSIS," Materials Today: Proceedings, vol. 4, no. 2, pp. 30433052, 2017.

10. K. Shirvanimoghaddam et al., "Carbon fiber reinforced metal matrix composites: Fabrication processes and properties," Composites Part A: Applied Science and Manufacturing, vol. 92, pp. 70-96, Jan. 2017

11. B. S. Hasu, S. M. Kumar, V. Chiranjeevi, "Experimental investigation for optimum process parameters in wire cut EDM process using Taguchi method," International Journal of Engineering and Advanced Technology, vol. 7, no. 2, p. 96-99, Dec. 2017.

12. A. S. Gore and N. G. Patil, "Wire electro discharge machining of metal matrix composites: A review," Procedia Manufacturing, vol. 20, pp. 41-52, 2018.

13. R. Garg and H. Singh, "Optimisation of process parameters for gap current in wire electrical discharge machining," International Journal of Manufacturing Technology and Management, vol. 25, no. 1/2/3, p. $161,2012$.

14. E. Karthick, J. Mathai, J. M. Tony, and S. K. Marikkannan, "Processing, Microstructure and Mechanical Properties of Al2O3 and SiC Reinforced Magnesium Metal Matrix Hybrid Composites,' Materials Today: Proceedings, vol. 4, no. 6, pp. 6750-6756, 2017.

\section{AUTHORS ProfiLe}

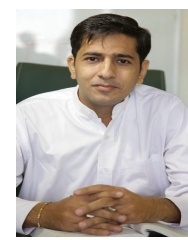

Er. Rohit Sharma is a research scholar (Ph.D, Mechanical Engineering student). His areas of interests include non-conventional machining, especially Wire EDM and Taguchi mathematical method. He is M.Tech from IKG Punjab Technical University, Punjab, India. Two journal publications and two conference proceedings of national and international level are accredited in his name. He is also a lifetime member of Indian Society for Technical Education (ISTE)

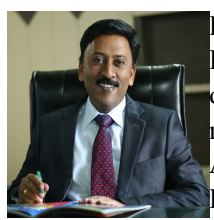

Dr. Vivek Aggarwal is Assistant Professor in IKG Punjab Technical University, Kapurthala, India. His areas of interest include conventional and non-conventional machining. He completed his Ph. D. from Dr. B.R. Ambedkar NIT, Jalandhar, his M. Tech. from I.K.Gujral PTU, Jalandhar and his B.E. from Thapar University, Patiala, Punjab, India. He is a life Member of Indian Society For Technica Education, New Delhi. He has been National Scholarship holder throughout his studies. Nine national and international journal publications, three national and international conferences are accredited to his name. He is also writer of four books and is a reviewer of a number of referred International Journals viz. Measurement (ELSEVIER), Journal of Engineering Manufacture - Part B (SAGE), Journal of the Brazilian Society of Mechanical Sciences and Engineering (SPRINGER), etc.

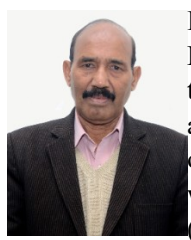

Prof. (Dr.) H. S. Payal is the Professor and Head of Department, SHRU, Dehradun. He has a rich experience of teaching and research of more than 39 years, along with also having previous 07 years of valuable experience in ordnance factory organization, Ministry of Defense. Along with ME (Mech Engg.), MBA (HRM), he also holds a PhD (Mech Engg.) degree from Thapar University, Patiala, Punjab, India. His areas of interests include non-conventional machining, tool and die design and manufacturing science. He has 21 publications in his name and is also the recepient of the Best Citizen Award.

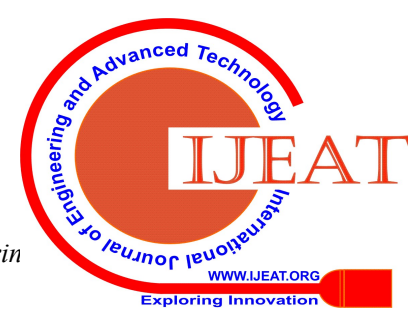

